\title{
Enhancement of the Bioactivity of 4, 5-dibromoimidazole by its Cobalt (II) Complex
}

\author{
${ }^{1}$ Duru I.A., ${ }^{2}$ Ngochindo R.I. and ${ }^{3}$ Duru C.E. \\ ${ }^{I}$ Department of Chemistry, Federal University of Technology Owerri, Imo State Nigeria \\ ${ }^{2}$ Department of Chemistry, University of Portharcourt, River State, Nigeria \\ ${ }^{3}$ Department of Chemistry, Alvan Ikoku Federal College of Education Owerri, Imo State Nigeria
}

\begin{abstract}
DBI) was synthesized and its structure elucidated using ${ }^{1} H$-NMR, ${ }^{13} C$-NMR, FT-IR and mass spectroscopy. Its activity on Streptococcus pyogenes, Staphylococcus aureus, Pseudomonas aeruginosa, Proteus spp, Aspergillus spp, Candida spp and Trichophyton spp was studied for possible antimicrobial properties. The compound showed no activity on Pseudomonas aeruginosa, Proteus spp, Aspergillus spp and Candida spp. while Streptococcus pyogenes and Staphylococcus aureus were slightly sensitive to it. The potency of this compound on these organisms was shifted by its transition metal complexes. A five to six fold enhancement in activity was observed with its $\mathrm{Co}^{2+}$ complex which remained potent even at lower concentrations. $\mathrm{Cr}^{3+}$ and $\mathrm{Cu}^{2+}$ complexes of the compound at higher concentrations showed a similar increase in sensitivity as the $\mathrm{Co}^{2+}$ complex. The $\mathrm{Fe}^{2+}$ complex of the compound however rendered the compound totally inactive against all the studied organisms.
\end{abstract}

Keywords: Antimicrobial potency, Dibromoimidazole, Metal complexes, Spectroscopy, Transition metal

\section{Introduction}

Imidazole and its derivatives have attracted considerable interests in recent years for their versatile properties in chemistry and pharmacology. Imidazole is a nitrogen-containing heterocyclic ring with immense biological and pharmaceutical importance. Its derivatives possess extensive spectrum of biological activities such as antibacterial [1-2], anticancer [3-5], antitubercular [6-9], antifungal [10-12], analgesic [13-15], and antiHIV [16] activities.

Halogenated compounds containing the imidazole moiety have shown a wide spectrum of activity against many organisms [17-19]. Many drug substances, such as antimicrobial and anticancer drugs exhibit drug action through complexation with the available bio-metals in vivo [20]. Interaction of various metal ions with antibiotics may enhance or suppress their antimicrobial activity but usually in many cases, the pharmacological activity of antibiotics, after complexation with metals, is enhanced as compared to that of the free ligands [21]. Some inactive biological ligands developed good antimicrobial properties upon chelation [22].

Reports on the biological activity of brominated imidazole and its complexes are scarce. In this study, 4,5-dibromoimidazole (DBI) would be synthesized and the biological activity of some of its complexes correlated with that of the pure compound.

\subsection{Synthesis of 4,5-dibromoimidazole}

\section{Methodology}

4,5-dibromoimidazole was synthesized by following the procedure by Stensio et al [23] with some modification. Imidazole $(1.36 \mathrm{~g})$ was added to a solution of sodium acetate $(20 \mathrm{~g})$ in acetic acid $(180 \mathrm{ml})$ and stirred for 10 minutes to dissolve. Half the volume of bromine $(9.6 \mathrm{~g})$ in anhydrous acetic acid $(20 \mathrm{ml})$ was then added and stirred for 20 minutes, giving a solution with pale yellow colour. Sodium acetate $(5 \mathrm{~g})$ was added to the solution with stirring, followed by the remaining portion of bromine in anhydrous acetic acid. Stirring was continued for 2.5 hours. The acetic acid was evaporated by heating to almost dryness and water $(300 \mathrm{ml})$ was added. The mixture was filtered and the precipitate was washed with water and dried.

\subsection{Preparation of 4,5-dibromoimidazole Metal Complexes}

All the complexes were prepared using the same procedure. 1 mmole of each hydrated metal salt were dissolved in $2 \mathrm{ml}$ of distilled water and added a drop at a time with continuous stirring to 2 mmoles of the DBI dissolved in $10 \mathrm{ml}$ of acetone. The mixture was stirred at room temperature for half an hour and allowed to stand. The metal complexes which precipitated afterwards were filtered through sintered glass crucible, washed with cold water and dried under vacuum at $50{ }^{\circ} \mathrm{C}$. The products were recrystallized with redistilled ethanol. 


\subsection{Characterization of Products}

DBI and its transition metal complexes were characterized by FT-IR, mass spectral and nuclear magnetic resonance spectroscopy.

FT-IR spectra were obtained using $\mathrm{KBr}$ discs and Nujol mull techniques on IR Spectrophotometer FTIR 8400 S Shimadzu in the $4000-450 \mathrm{~cm}^{-1}$ range. The important IR bands indicating the formation of the compound and complexes were studied.

Mass spectra were obtained from Shimadzu LCMS-2010EV Liquid Chromatography Mass Spectrometer, ESI.

NMR spectra were recorded in $\mathrm{D}_{2} \mathrm{O}$ and DMSO- $\mathrm{d}_{6}$, on a Varian 400-MR Magnetic Resonance Spectrometer.

\subsection{Studies of Antimicrobial Activity of Products}

\subsubsection{Collection of Microbial Cultures}

Pure clinical isolates of Streptococcus pyogenes, Staphylococcus aureus, Pseudomonas aeruginosa, Proteus spp, Aspergillus spp, Candida spp and Trichophyton spp were collected from the Microbiology Department of the Federal Medical Center Owerri, Imo State Nigeria. A microbial loop was used to remove a colony of each organism from the pure culture and transferred into liquid broth (Nutrient broth) and incubated for 24 hours at $37^{\circ} \mathrm{C}$. These were maintained in sterile conditions.

\subsubsection{Determination of antimicrobial Activity of Ligand and its Complexes}

Paper disc diffusion method was used for the determination of the antibacterial activity of the ligand and its complexes.

The equipments, petri dishes, flasks, pipettes, tweezers, forceps and wire loops were first thoroughly washed with detergent and distilled water then sterilized by dry heat method in a hot air oven at $200{ }^{\circ} \mathrm{C}$ for 2 hours. The sterilized equipments were kept under laminar air flow where subsequent procedure was completed. Other materials and media were sterilized by autoclaving at $120^{\circ} \mathrm{C}$ for 20 minutes.

Solutions of the DBI and its complexes containing $200 \mathrm{mg} / \mathrm{ml}$ of each compound were prepared and absorbed on the paper disc prepared from Whatman filter papers $(3 \mathrm{~mm}$ size) with the help of a micropipette. The solutions were then serial diluted to obtain $100 \mathrm{mg} / \mathrm{ml}, 50 \mathrm{mg} / \mathrm{ml}$ and $25 \mathrm{mg} / \mathrm{ml}$ concentrations and each concentration applied on separate filter paper discs. These discs were left in an incubator for 24 hours at $37^{\circ} \mathrm{C}$. Antimicrobial activity of DBI and its metal complexes were determined separately. A sterilized forceps was used for the application of the paper discs with different concentrations of the prepared solutions on the already incubated agar plates. When the discs were applied, they were incubated at $37^{\circ} \mathrm{C}$ for 24 hours. The diameter of inhibition zone was measured.

\section{Results And Discussion}

The product obtained had a mass of $3.6 \mathrm{~g}$, which is equivalent to a yield of $64 \%$ with a melting point ranging between $226-227^{\circ} \mathrm{C}$.

The structure of DBI was supported by its mass spectrum which exhibited a molecular ion peak corresponding to the formula $\mathrm{C}_{3} \mathrm{H}_{2} \mathrm{~N}_{2} \mathrm{Br}_{2}\left(\mathrm{M}^{+}=227\right)$ with the assumption that one of the bromine atoms is of the $\mathrm{M}+1$ isotope. The other peak observed was $\mathrm{m} / \mathrm{z} 199$ and the remaining mass of 28 was supposed to have been lost as $\mathrm{H}_{2} \mathrm{CN}$ which is a common species eliminated in aromatic nitrogen heterocycles [24]. This assignment is shown in scheme 1 .

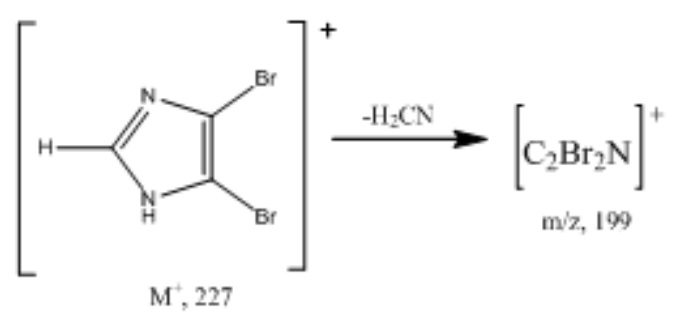

\section{Scheme 1: Fragmentation pattern of 4,5-dibromoimidazole}

The colours of the products and their characteristic bands in the IR spectrum are shown in Table 1. The frequencies $3464 \mathrm{~cm}^{-1}, 500 \mathrm{~cm}^{-1}, 1650 \mathrm{~cm}^{-1}, 1179 \mathrm{~cm}^{-1}$ and $1421 \mathrm{~cm}^{-1}$ observed in the scan were assigned to $\mathrm{N}-$ $\mathrm{H}, \mathrm{C}-\mathrm{Br}, \mathrm{C}=\mathrm{N}, \mathrm{C}-\mathrm{N}$ and $\mathrm{C}=\mathrm{C}$ respectively and are the main functional groups in DBI. The marked difference in the absorbance value of DBI at $3464 \mathrm{~cm}^{-1}(\mathrm{~N}-\mathrm{H})$ when compared with those of its complexes is an indication that the $\mathrm{N}-\mathrm{H}$ in the imidazole ring may be involved in the complexation. 
Table 1: Colour and IR data of DBI and its coordination compounds

\begin{tabular}{|l|l|l|l|l|l|l|}
\hline Compound & Colour & $v(N-H) \mathrm{cm}^{-1}$ & $v(C-B r) \mathrm{cm}^{-1}$ & $v(C=N) \mathrm{cm}^{-1}$ & $v(C-N) \mathrm{cm}^{-1}$ & $v(C=C) \mathrm{cm}^{-1}$ \\
\hline TBI & White & $3464 \mathrm{vw}$ & $500 \mathrm{~s}$ & $1650 \mathrm{~m}$ & $1178 \mathrm{~m}$ & $1421 \mathrm{w}$ \\
\hline$[\mathrm{Co}(\mathrm{DBI})]$ & Pink & $3172 \mathrm{~m}$ & $494 \mathrm{~m}$ & $1648 \mathrm{w}$ & $1177 \mathrm{~m}$ & $1420 \mathrm{~m}$ \\
\hline$[\mathrm{Cr}(\mathrm{DBI})]$ & Green & $3227 \mathrm{br}$ & $481 \mathrm{~m}$ & $1645 \mathrm{~s}$ & $1178 \mathrm{~m}$ & $1421 \mathrm{~m}$ \\
\hline$[\mathrm{Cu}(\mathrm{DBI})]$ & Lemon & $3202 \mathrm{br}$ & $498 \mathrm{~m}$ & $1647 \mathrm{~s}$ & $1175 \mathrm{~m}$ & $1420 \mathrm{~m}$ \\
\hline$[\mathrm{Fe}(\mathrm{DBI})]$ & Orange & $3154 \mathrm{br}$ & $498 \mathrm{~m}$ & $1648 \mathrm{~s}$ & $1177 \mathrm{~m}$ & $1422 \mathrm{~m}$ \\
\hline
\end{tabular}

$\mathrm{vw}=$ very weak; $\mathbf{m}=$ medium; $\mathbf{w}=$ weak; $s=$ strong; br $=$ broad

The ${ }^{1} \mathrm{H}-\mathrm{NMR}$ and ${ }^{13} \mathrm{C}-\mathrm{NMR}$ of DBI in $\mathrm{D}_{2} \mathrm{O}$ and DMSO only showed the peaks for the solvent and this confirmed the insolubility of the compound in these two common NMR solvents as was observed during the study.

The activities of DBI and its $\mathrm{Co}^{2+}, \mathrm{Cr}^{3+}, \mathrm{Cu}^{2+}$ and $\mathrm{Fe}^{2+}$ complexes on Streptococcus pyogenes, Staphylococcus aureus, Pseudomonas aeruginosa, Proteus spp, Aspergillus spp, Candida spp and Trichophyton spp are shown in Table 2 and Table 3.

Table 2: Activity of DBI and its complexes against some bacteria strains

\begin{tabular}{|c|c|c|c|c|c|}
\hline \multirow[t]{2}{*}{ Samples } & \multirow{2}{*}{$\begin{array}{l}\text { Concentrations } \\
(\mathrm{mg} / \mathrm{ml})\end{array}$} & \multicolumn{3}{|c|}{ Diameter of Zone of Inhibition (mm) } & \multirow[b]{2}{*}{$\begin{array}{l}\text { Proteus } \\
\text { spp }\end{array}$} \\
\hline & & $\begin{array}{l}\text { Streptococcus } \\
\text { pyogenes }\end{array}$ & $\begin{array}{l}\text { Pseudomonas } \\
\text { aeruginosa }\end{array}$ & $\begin{array}{l}\text { Staphylococcus } \\
\text { aureus }\end{array}$ & \\
\hline \multirow{4}{*}{ DBI } & 200 & 2 & - & 2 & - \\
\hline & 100 & - & - & - & - \\
\hline & 50 & - & - & - & - \\
\hline & 25 & - & - & - & - \\
\hline \multirow{4}{*}{ DBI-Co } & 200 & 12 & 10 & 12 & - \\
\hline & 100 & 8 & 6 & 6 & - \\
\hline & 50 & 6 & 4 & 4 & - \\
\hline & 25 & 2 & 2 & 4 & - \\
\hline \multirow{4}{*}{ DBI-Cr } & 200 & 8 & 8 & 8 & - \\
\hline & 100 & 4 & 6 & 6 & - \\
\hline & 50 & - & 2 & - & - \\
\hline & 25 & - & - & - & - \\
\hline \multirow{4}{*}{ DBI-Cu } & 200 & 10 & 10 & 6 & 6 \\
\hline & 100 & 4 & 6 & 2 & 4 \\
\hline & 50 & - & 2 & - & - \\
\hline & 25 & - & - & - & - \\
\hline \multirow{4}{*}{ DBI-Fe } & 200 & - & - & - & - \\
\hline & 100 & - & - & - & - \\
\hline & 50 & - & - & - & - \\
\hline & 25 & - & - & - & - \\
\hline Levofloxacin & 2 & 14 & 14 & 10 & 8 \\
\hline
\end{tabular}

Table 3: Activity of DBI and its complexes against some fungi strains

\begin{tabular}{|c|c|c|c|c|}
\hline \multirow[t]{2}{*}{ Samples } & \multirow{2}{*}{$\begin{array}{l}\text { Concentrations } \\
(\mathrm{mg} / \mathrm{ml})\end{array}$} & \multicolumn{3}{|c|}{ Diameter of Zone of Inhibition ( $\mathrm{mm}$ ) } \\
\hline & & $\begin{array}{l}\text { Aspergillus } \\
\text { spp }\end{array}$ & Candida spp & Trichophyton spp \\
\hline \multirow{4}{*}{ DBI } & 200 & - & - & 2 \\
\hline & 100 & - & - & - \\
\hline & 50 & - & - & - \\
\hline & 25 & - & - & - \\
\hline \multirow{4}{*}{ DBI-Co } & 200 & 10 & 12 & 10 \\
\hline & 100 & 6 & 8 & 4 \\
\hline & 50 & 2 & 6 & 4 \\
\hline & 25 & 2 & 2 & 2 \\
\hline \multirow{4}{*}{ DBI-Cr } & 200 & - & 6 & 8 \\
\hline & 100 & - & 2 & 4 \\
\hline & 50 & - & - & - \\
\hline & 25 & - & - & - \\
\hline \multirow{4}{*}{ DBI-Cu } & 200 & - & - & 6 \\
\hline & 100 & - & - & 4 \\
\hline & 50 & - & - & 2 \\
\hline & 25 & - & - & - \\
\hline \multirow{4}{*}{ DBI-Fe } & 200 & - & - & - \\
\hline & 100 & - & - & - \\
\hline & 50 & - & - & - \\
\hline & 25 & - & - & - \\
\hline Ketoconazole & 200 & - & - & 2 \\
\hline
\end{tabular}


DBI showed very little and in some cases no activity against the bacteria and fungi strains used for the study. This shows that the compound has an insignificant medicinal value, which accounts for why it might not have been considered as a drug substance. It was totally rendered inactive upon complexation with $\mathrm{Fe}^{2+}$ confirming the fact that some transition metals can reduce or remove the initial activity of a ligand compound complexed with them [21].

However, on complexation with $\mathrm{Cu}^{2+}$ and $\mathrm{Cr}^{2+}$ at a concentration of $200 \mathrm{mg} / \mathrm{ml}$, the activity of the compound was marginally increased with better activity shown against the bacteria strains than the fungi. With a drop in the concentration of these complexes to $50 \mathrm{mg} / \mathrm{ml}$ their activity became averagely similar to what was obtained in the uncomplexed form of the DBI.

The $\mathrm{Co}^{2+}$ complex of the DBI greatly enhanced its activity against all the studied organisms except Proteus spp, only equaling the activity of the uncomplexed DBI at a very low concentration of $25 \mathrm{mg} / \mathrm{ml}$. This complex also showed a fairly good activity against these organisms compared to the standard antibacterial drug levofloxacin. When measured against the antifungal drug ketoconazole which has an imidazole moiety in the compound, it showed a broader spectrum of activity and was more effective than the drug compound even at lower concentrations. This makes DBI $\mathrm{Co}^{2+}$ complex a better and more effective antifungal agent than an antibacterial one.

\section{Conclusion}

This study has shown 4,5-dibromoimidazole to be a weakly bioactive compound against the studied microbes. Its activity against the microbial strains can be increased or decreased depending on the type of transition metal used for its complexation. Its transition metal complexes were shown to be better antifungal agents than antibacterial when compared with known standard drug agents.

\section{Acknowledgements}

We are very grateful to the Education Trust Fund of Nigeria, for their financial assistance. Our gratitude also goes to Asclepia Outsourcing Solutions Destelbergen Belgium, for providing spectroscopic characterization.

\section{References}

[1]. X. Lu, X. Liu, B. Wan, S.G. Franzblau, L. Chen, C, Zhou and Q. You, Synthesis and evaluation of anti-tubercular and antibacterial activities of new 4-(2,6-dichlorobenzyloxy)phenyl thiazole, oxazole and imidazole derivatives, European Journal of Medicinal Chemistry, 49, 2012, 164-171.

[2]. A. K. Jain, V. Ravichandran, M. Sisodiya, and R. K. Agrawal, Synthesis and antibacterial evaluation of 2-substituted-4,5-diphenyl$\mathrm{N}$-alkyl imidazole derivatives, Asian Pacific Journal of Tropical Medicine, 3(6), 2010, 471-474.

[3]. H. M. Alkahtani, A. Y. Abbas, and S. Wang, Synthesis and biological evaluation of benzo[d]imidazole derivatives as potential anticancer agents, Bioorganic and Medicinal Chemistry Letters, 22(3), 2012, 1317-1321.

[4]. Y. Özkay, I. Işikdağ, Z. Incesu, and G. Akalin, Synthesis of 2-substituted-N-[4-(1-methyl-4,5-diphenyl-1H-imidazole-2-yl) phenyl] acetamide derivatives and evaluation of their anticancer activity, European Journal of Medicinal Chemistry, 45(8), 2010, 33203328 .

[5]. X. Wang, L. Liu, Y. Li et al., Design, synthesis and biological evaluation of novel hybrid compounds of imidazole scaffold-based 2benzylbenzofuran as potent anticancer agents, European Journal of Medicinal Chemistry, 62, 2013, 111-121.

[6]. S. Lee, S. Kim, M. Yun, y.s. Lee, S.N. Cho, T. Oh and P. Kim, Synthesis and antitubercular activity of monocyclic nitroimidazoles: insights from econazole, Bioorganic and Medicinal Chemistry Letters, 21(5), 2011, 1515-1518.

[7]. S. G. Alegaon, K. R. Alagawadi, P. V. Sonkusare, S. M. Chaudhary, D. H. Dadwe, and A. S. Shah, Novel imidazo[2,1b] $[1,3,4]$ thiadiazole carrying rhodanine-3-acetic acid as potential antitubercular agents, Bioorganic and Medicinal Chemistry Letters, 22(5), 2012, 1917-1921.

[8]. J. Pandey, V.K. Tiwari, S.S. Verma, V. Chaturvedi, S. Bhatnagar, S. Sinha, A.N. Gaikwad and R.P. Tripathi, Synthesis and antitubercular screening of imidazole derivatives, European Journal of Medicinal Chemistry, 44(8), 2009, 3350-3355.

[9]. A. Fassihi, Z. Azadpour, N. Delbari, L. Saghaie, H.R. Memarian, R. Sabet, A. Albozi, R. Miri, B. Pourabbas, J. Mardaneh, P. Mousavi, B. Moeinifard and H. Sadeghi-Aliabadi, Synthesis and antitubercular activity of novel 4-substituted imidazolyl-2,6dimethyl-N3,N5-bisaryl-1,4-dihydropyridine-3,5-dicarboxamides, European Journal of Medicinal Chemistry, 44(8), 2009, 32533258 .

[10]. D. Zampieri, M. G. Mamolo, E. Laurini, G. Scialino, E. Banfi, and L. Vio, Antifungal and antimycobacterial activity of 1-(3,5diaryl-4,5-dihydro-1H-pyrazol-4-yl)-1H-imidazole derivatives, Bioorganic and Medicinal Chemistry, 16(8), 2008, 4516-4522, 2008.

[11]. D. de Vita, L. Scipione, S. Tortorella, P. Mellini, B. Di Rienzo, G. Simonetti, F.D. D’Auria, S. Panella, R. Cirilli, R. Di Santo and A.T. Palamara, Synthesis and antifungal activity of a new series of $2-(1 \mathrm{H}$-imidazol-1-yl)- 1-phenylethanol derivatives, European Journal of Medicinal Chemistry, 49, 2012, 334-342.

[12]. W. C. Yang, J. Li, J. Li, Q. Chen, and G. F. Yang, Novel synthetic methods for N-cyano-1H-imidazole-4-carboxamides and their fungicidal activity, Bioorganic and Medicinal Chemistry Letters, 22(3), 2012, 1455-1458.

[13]. Ü. Uçucu, N. G. Karaburun, and I. Işikdag, Synthesis and analgesic activity of some 1-benzyl-2-substituted-4,5-diphenyl-1Himidazole derivatives, Farmaco, 56(4), 2001, 285-290.

[14]. S. Kankala, R.K. Kankala, G. Prasad, N. Thota, S. Nerella, M.R. Gangula, H. Guguloth, M. Kagga, R. Vadde and C.S. Vasam, Regioselective synthesis of isoxazole-mercaptobenzimidazole hybrids and their in vivo analgesic and anti-inflammatory activity studies, Bioorganic and Medicinal Chemistry Letters, 23(5), 2013, 1306-1309. 
[15]. M. Gaba, D. Singh, S. Singh, V. Sharma, and P. Gaba, Synthesis and pharmacological evaluation of novel 5-substituted-1(phenylsulfonyl)-2-methylbenzimidazole derivatives as anti-inflammatory and analgesic agents, European Journal of Medicinal Chemistry, 45(6), 2010, 2245-2249.

[16]. P. Zhan, X. Liu, J. Zhu, Z. Fang, Z. Li, C. Pannecouque and E.D. Clercq, Synthesis and biological evaluation of imidazole thioacetanilides as novel non-nucleoside HIV-1 reverse transcriptase inhibitors, Bioorganic and Medicinal Chemistry, 17(16), 2009, 5775-5781.

[17]. F. Bellina, S. Cauteruccio and R. Rossi, Synthesis and biological activity of vicinal diaryl-substituted 1H-imidazoles, Tetrahedron, 63(22), 2007, 4571-4624.

[18]. Y. Liu, X. Sun, D. Yin and F. Yuan, Synthesis and biological activity of chalcones-imidazole derivatives, Research on Chemical Intermediates, 39(3), 2012, 1037-1048.

[19]. M.A. Iradyan, G.M. Stepanyan, A.Kh. Aivazyan, V.S. Mirzoyan, Sh. A. Avetyan, Z.S. Izaakyan, D.Sh. Manucharyan, M.Kh. Dayan and B.T. Garibdzhanyan, Imidazoles.XVI. Synthesis and biological activity of some 1-benzyl-4-nitroimidazole-5-thioacetic acids, Pharmaceutical Chemistry Journal, 15(2), 1981, 97-103.

[20]. M. N. Hughes, The Inorganic Chemistry of Biological Processes, (2 ${ }^{\text {nd }}$ Ed., Wiley, New York, 315, 1981).

[21]. M. S. Iqbal, A. R. Ahmad, M. Sabir and S. M. Asad, Preparation, characterization and biological evaluation of copper(II) and zinc(II) complexes with cephalexin, J. Pharm. Pharmacol., 51(4), 1999, 371-375.

[22]. N. Nawar and N. M. Hosny, Synthesis, spectral and antimicrobial activity studies of o-aminoacetophenone ohydroxybenzoylhydrazone, Transition Metal Chemistry, 25, 2000, 1-8.

[23]. K. Stensio, K. Wahlberg and R. Wharen, Synthesis of brominated imidazoles, Acta Chemica Scandinavica, 27, 1973, 2179-2183.

[24]. D.B. Mistry, A handbook of spectroscopic data chemistry (UV, IR, PMR, CNMR and Mass spectroscopy) (Oxford Book Company, Jaipur, India, 2009, 233) 